\title{
Beberapa Pengalaman Menghadapi Serangan Rayap Dan Upaya Pencegahannya pada Saat Pra dan Pasca Konstruksi
}

\author{
Imam Prayogo \\ Dosen D3 Teknik Sipil FTSP-ITS \\ email:imam@ce.its.ac.id
}

\begin{abstract}
ABSTRAK
Serangan rayap akhir-akhir ini telah menjadi perhatian para ahli konstruksi, terutama bangunan gedung. Sebanding dengan naiknya jumlah pihak yang dirugikan akibat serangannya, semakin besar pula nilai kerugian materi maupun non materi yang ditimbulkan. Sehingga kemajuan teknologi pengendaliannyapun ikut semakin bervariasi. Dari beberapa pengalaman yang terpantau selama ini, baik di lingkungan kampus ITS maupun di tempat lain pada tingkat regional dan nasional, serangan akibat rayap sangat mungkin untuk dikendalikan mulai dari tahap Pra Konstruksi (Perencanaan) hingga Pasca Konstruksi (Operasi dan Perawatan). Rencana pengendalian cara Pisik, pada tahap perencanaan konstruksi dan pengendalian Non Pisik di tahap Operasi \& Perawatan yang telah dilakukan, diyakini lebih berhasil guna, karena cara demikian lebih rasional atau tidak emosional serta terjamin kelanjutannya. Dengan demikian tipologi Manajemen Konstruksi yang berperan selama siklus hidup proyek (project life cycle) dapat dimanfaatkan bagi pengendalian rayap yang menggunakan pendekatan rasional.
\end{abstract}

Kata kunci: Rayap, Serangan, Pengendalian, Pra-konstruksi, Pasca-konstruksi

\section{PENDAHULUAN}

Serangan rayap dari waktu ke waktu diindikasikan tidak ada penurunan yang signifikan, tetapi sebaliknya justru ada gejala peningkatan yang cukup mengkhawatirkan bahayanya. Kondisi ini dapat dilihat dari semakin seringnya didengar keluhan tentang serangan rayap, munculnya banyak promosi maupun penawaran pengendalian serangan rayap dan banyaknya perusahaan Pest Control Operator (PCO) serta semakin seringnya diadakan diskusi, seminar ataupun pelatihan bagi upaya pengenalan kehidupan rayap beserta cara pengendaliannya. Disamping itu belum terhitung pula gigihnya para peneliti di dalam melaksanakan penelitian bagi upaya membongkar segala misteri tentang rayap.

Tanpa bermaksud mengecilkan arti perlindungan terhadap lingkungan hidup, segala upaya pembasmian rayap sangat diharapkan oleh banyak pihak, terutama bagi mereka yang pernah mengalami kerugian akibat serangan rayap. Bahkan lebih dari itu sering muncul pemikiran seandainya di lingkungan sekitar kita bisa terbebaskan dari kehidupan rayap, niscaya segala kerugian akibat serangan rayap dapat dieliminasi, terlepas dari hal tersebut akan dapat menimbulkan masalah pengurangan kesempatan kerja para PCO. Apalagi sekiranya pembasmian tersebut dapat dilaksanakan dalam waktu secepatnya dan sangat jelas bukti keberhasilannya.

Secara psikologis harapan tersebut muncul dari para penderita kerugian akibat serangan rayap, untuk meluapkan rasa dendam terhadap rayap. Namun pengalaman menunjukkan bahwa pemberantasan rayap secara emosional justru sama dengan memberikan kesempatan berikutnya bagi rayap untuk melakukan penyerangan pada obyek yang sama atau di dekatnya. Hal tersebut merupakan salah satu bentuk kelemahan di dalam usaha pembasmian rayap.

Dengan telah diterbitkannya SNI-03-24041991, maka segala usaha 'pembasmian' rayap menjadi lebih terarah pada usaha 'pengendalian' rayap, baik pada perlakuan pra konstruksi (pre-construction treatment) maupun perlakuan pasca konstruksi (postconstruction treatment).

Berikutnya untuk melindungi kayu elemen maupun komponen bangunan telah diterbitkan pula SNI-03-2405-1991. Diharapkan mencegah kerugian akibat serangan rayap tidak harus menimbulkan gangguan pada lingkungan hidup, termasuk kerusakan lingkungan yang diakibatkan oleh musnahnya kehidupan rayap dari sekitar 
kita. Adanya standar pengendalian rayap seperti tersebut di atas telah membuka pula wacana kegiatan pengendalian rayap dari bentuk usaha sporadic represive, yang mengandalkan upaya pembasmian rayap hanya dititik serangannya, menjadi systemic institutional yaitu memasukkan proses dan prosedur pengendalian rayap mulai dari tahap perencanaan konstruksi hingga operasi dan perawatannya.

\section{SERANGAN RAYAP \& KERUSAKANNYA}

Pada saat awal pembangunan gedung, jarang sekali pihak-pihak yang terkait dengan proses pelaksanaan pembangunan tersebut sadar, memahami atau waspada terhadap serangan rayap. Kalaupun ada yang mengingatkan, tidak semua pihak dapat segera memahami atau mendukung, apalagi bila dijelaskan segala proses pencegahan sebagai bagian dari pengendalian, beserta nilai nominal pembiayaannya. Selama ini bahaya serangan rayap selalu dihubungkan dengan kayu atau bahan sejenisnya yang mengandung selulosa dan tidak diawetkan maupun yang bermutu rendah, sehingga bila diyakini konstruksi bangunan gedung telah terbuat dari bahan bangunan non kayu, diantaranya beton, baja dan tembok batu, maka dianggap telah terbebaskan dari serangan rayap.

Fakta di lapangan telah memberikan penjelasan yang sangat baik bagi kita semua, dimana bangunan gedung yang lantai terbawahnya terbuat dari konstruksi beton bertulang, berada pada ketinggian 1,5m di atas permukaan tanah tetap terserang rayap setelah mencapai umur bangunan antara 15 - 20 tahun, dengan bentuk kerusakan yang sangat fatal, yaitu memerlukan penggantian komponen bangunan yang terbuat dari kayu, meskipun berada pada ketinggian $>7 \mathrm{~m}$. Seperti yang ditunjukkan pada contoh seperti pada gambar 3,4 dan 5. Bentuk keteledoran, kesalahan pelaksanaan dan kelengahan yang menjadi peluang besar bagi serangan rayap.

Selain dari itu hasil pemeriksaan di laboratorium IPB, pada komplek bangunan tersebut telah ditemukan tidak kurang dari 9 spesies rayap yang hidup dan menyerang semua bahan bangunan yang bisa dijadikan mangsanya. Sasaran dan tingkat kerusakan yang ditimbulkan dapat dilihat pada Tabel 1 di bawah ini.

Tabel 1. Kerusakan komponen dan elemen bangunan akibat serangan rayap

\begin{tabular}{|c|c|c|c|c|}
\hline \multirow{3}{*}{ No } & \multirow{2}{*}{\multicolumn{2}{|c|}{ NFONEN/ELEMEN }} & \\
\hline & & BAHAN & POSISI & KERUSAKAN \\
\hline & Struktur atap (kude-kude) & Kayu & $10.5 \times 1.5 \mathrm{~m}$ & 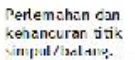 \\
\hline 2. & Rangka daford & Kayv & $2,8+1.5 \mathrm{~m}$ & $\begin{array}{l}\text { Perlemathan can } \\
\text { kencincuran } \text { ytk } \\
\text { simpul/oztarg }\end{array}$ \\
\hline$\frac{1}{4 .}$ & 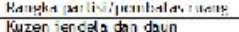 & Kan: & $\frac{1,1,-2,8 \text { in }}{1,5+0,80 \pi}$ & 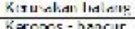 \\
\hline i. & |Biwin & & & \\
\hline 6. & 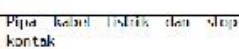 & $\begin{array}{l}\text { Pirvif } \\
\text { Pasjik }\end{array}$ & $1, x-1,000$ & $\begin{array}{l}\text { Tisivi inamp } \\
\text { kembara }\end{array}$ \\
\hline
\end{tabular}

Sumber : Survey dan Pengendalian rayap di kampus ITS, 1996-2000)

Dari tabel di atas nampak bahwa serangan rayap terhadap mangsanya tidak hanya menimbulkan kerusakan pada bahan bangunan kayu, tetapi juga dari bahan yang lain. Meskipun tidak dimangsa oleh rayap, pipa besi kabel listrik dan stop kontak plastik dapat mengalami kerusakan akibat terisi liang kembara, sehingga listrik tidak dapat berfungsi secara normal atau rusak. Dengan demikian patut untuk diperhatikan bahwa serangan rayap tidak selalu dalam bentuk memangsa sasarannya tetapi juga dapat melapisi atau menimbun dengan liang kembaranya.

Perlu diketahui bahwa terdapat ratusan jenis/species rayap di Indonesia (Nandika, D.2003. RAYAP biologi dan pengendaliannya), beberapa diantaranya memang mempunyai kemampuan menyerang sasarannya dengan sangat baik, meskipun sasaran tersebut berada jauh di atas permukaan tanah. Sehingga tidak semua pihak memahami secara baik dan tepat perilaku dari jenis rayap ini kecuali para ahli. Demikian pula sebaliknya daya serang yang laten dari rayap tersebut sering dianggap ringan oleh para ahli bangunan, terutama yang belum memahaminya.

\section{PENCEGAHAN SERANGAN SAAT PRA DAN PASCA KONSTRUKSI}

Sebagaimana telah disebutkan di atas pada saat ini telah ada standar bagi pencegahan serangan rayap dalam bangunan dengan SNI03-2405-1991 dan SNI-03-2404-1991. Dengan telah adanya standar ini, di satu pihak menunjukkan bahwa upaya pencegahan serangan rayap telah semakin maju, di pihak lain menjelaskan bahwa kegiatan 
pengendalian rayap telah memperoleh dukungan dari berbagai disiplin ilmu.

Oleh sebab itu, secara teknologi bangunan, pencegahan serangan rayap sudah dapat dimulai sejak akan dibangunnya suatu gedung (pra konstruksi), meskipun obsesi ini merupakan kegiatan yang masih jarang terjadi, karena memerlukan kerjasama dengan berapa ahli dari beberapa disiplin ilmu, namun telah dicoba dan kemungkinan berhasil baik. Selama ini pencegahan serangan rayap sebelum pembangunan gedung lebih banyak dalam bentuk pengawetan bahan bangunan, terutama kayu.

Secara kelembagaan (institusional), pencegahan serangan rayap pra kontruksi juga dapat dimasukkan ke dalam struktur organisasi pembangunan maupun siklus hidup proyek yang memanfaatkan jasa konsultan Manajemen Konstruksi seperti yang terlihat pada gambar 1 di bawah ini.

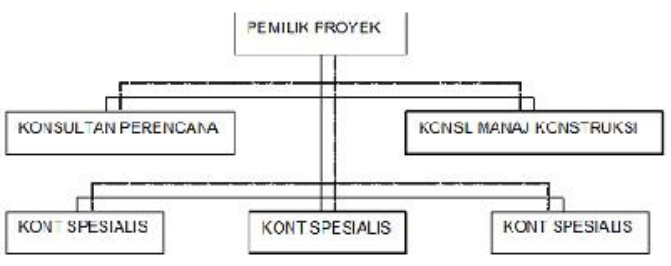

Gambar 1. Bentuk organisasi proyek dengan sistem Manajemen Konstruksi.

Karena proyek dengan sistem/tipologi Manajemen Konstruksi memanfaatkan jasa konsultan Manajemen Konstruksi sejak dari Pengembangan Konsep/Perencanaan sampai dengan awal Operasi Perawatan bangunan, maka konsep pencegahan serangan rayap yang bersifat sistematis, terorganisasi dan lebih mengedepankan usaha prefentip, sudah dapat disusun dan dimasukkan ke dalam rancangan bangunan gedung tersebut. Bila pelaksanaan pencegahannya dilaksanakan saat pra konstruksi, maka pengendaliannya dapat dilakukan oleh kontraktor spesialis namun tetap berada pada kendali maupun koordinasi pemilik dan konsultan Manajemen Konstruksi. Perhitungan biaya bagi kegiatan ini dapat dilihat pada Pedoman Teknis Pembangunan Bangunan Gedung Negara No 295/KPTS/CK/1997, yang diperbaharui menjadi No 332/KPTS/M/2002.
Apalagi bila di dalam pelaksanaan pembangunan proyek tersebut juga mensyaratkan dikerjakan oleh kontraktor utama/kontraktor spesialis yang telah mempunyai sertifikat ISO 9002, maka proses pelaksanaan pencegahan serangan rayap dapat mengikuti system elements nya, selanjutnya pengawasan mutu pekerjaan semakin tajam dan sistematis. Pengalaman selama ini di ITS maupun di tempat lain telah menunjukkan bahwa kegiatan pencegahan serangan rayap yang dimulai dari saat perancangan bangunan telah menghasilkan penghematan biaya preconstruction treatment, karena pekerjaan struktur dimanfaatkan juga sebagai 'tirai' penghambat serangan rayap, sehingga menambah tingkat kepastian prestasi PCO yang bekerja di tahap pra konstruksi, serta meningkatkan kualitas pelaksanaan struktur dan arsitektur bangunan tersebut.

Dalam hal usaha pencegahan serangan rayap saat pra konstruksi terpaksa harus diikuti dengan usaha pengendalian serangan rayap pasca konstruksi, maka usaha yang berorientasi pada kegiatan yang sistematis dan melembaga tetap dijadikan pegangan. Dari pengalaman selama ini, diperoleh fakta bila kegiatan pengendalian dapat dilaksanakan dengan orientasi di atas, maka bisa dihindarkan kesulitan dalam menentukan jenis pekerjaan pengendalian, volume pekerjaan, metode pelaksanaan dan spesifikasi kualitas kegiatan post construction treatment yang harus dipenuhi. Kesulitan di atas patut dihindarkan agar pelaksanaan program pengendalian rayap memenuhi kriteria akuntabilitas yang baik.

Sebaliknya jika tidak ada kejelasan pada program maupun prosedur pengendalian yang dapat dipertanggung jawabkan, maka pelaksanaan kegiatan pengendalian rayap akan lebih mengutamakan kesepakatan negosiasi harga satuan pekerjaan antara Pengguna Jasa dengan Pemberi Jasa serendah mungkin atau sehemat mungkin, sehingga kualitas/effektifitas di dalam memberikan pelayanan dan jaminan pada Pengguna Jasa tidak tercukupi.

Pengendalian rayap pasca konstruksi yang dilaksanakan secara sistematis dan melembaga juga akan dapat memberi nilai tambah bagi hasil karya perencanaan gedung 
tersebut, karena di dalam program Operasi dan Pemeliharaan gedung tersebut juga akan dilakukan kegiatan evaluasi, koordinasi dan pengendalian sedemikian rupa sehingga umur pelayanan dan kinerja gedung atau kenyamanan penghuni gedung bertambah lama.

Semakin baik lagi jika di dalam program pengendalian rayap tersebut juga dimasukkan kriteria perlindungan terhadap lingkungan hidup dan bila sekiranya harus melakukan eliminasi terhadap kehidupan koloni rayap di sekitar kita sebaiknya hanya dilaksanakan oleh PCO yang telah mempunyai otorisasi (authorized PCO) bagi pekerjaan tersebut yang saat ini mulai banyak ditunjuk oleh pemegang merk.

Satu catatan perlu diingat, bahwa kalau sampai menjumpai adanya serangan rayap di lingkungan kita, jangan panik dan emosional, karena serangan rayap tidak akan menghabiskan mangsanya atau meruntuhkan sasarannya dalam waktu semalam. Bersikaplah tenang, hubungi pihak-pihak yang ahli dan berkompeten dalam pelaksanaan pengendalian rayap, agar diperoleh hasil yang bermutu baik.

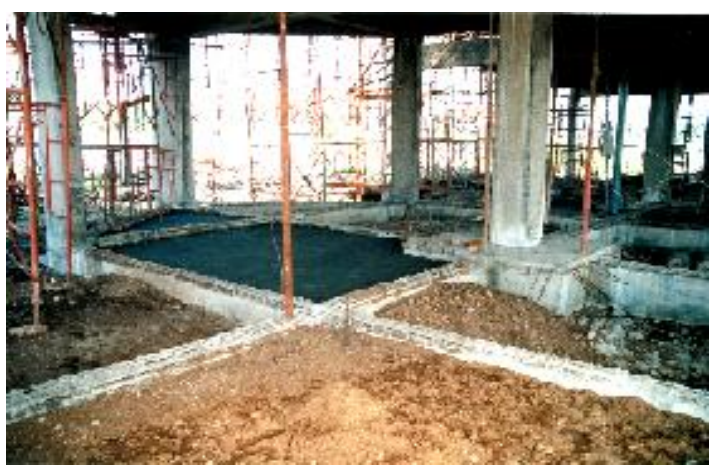

Gambar 2. Pekerjaan persiapan pencegahan rayap pra konstruksi

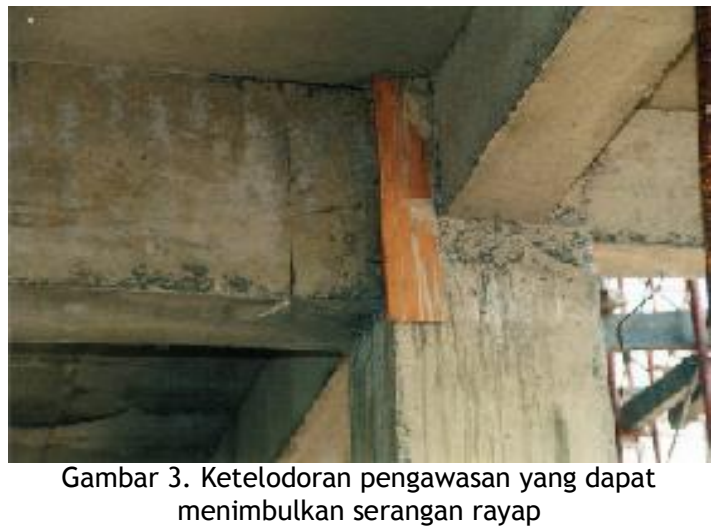

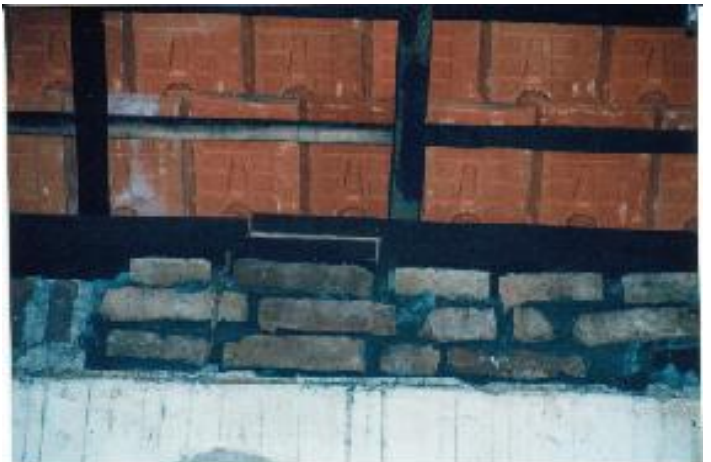

Gambar 4. Kesalahan pelaksanaan yang memberi peluang pada rayap

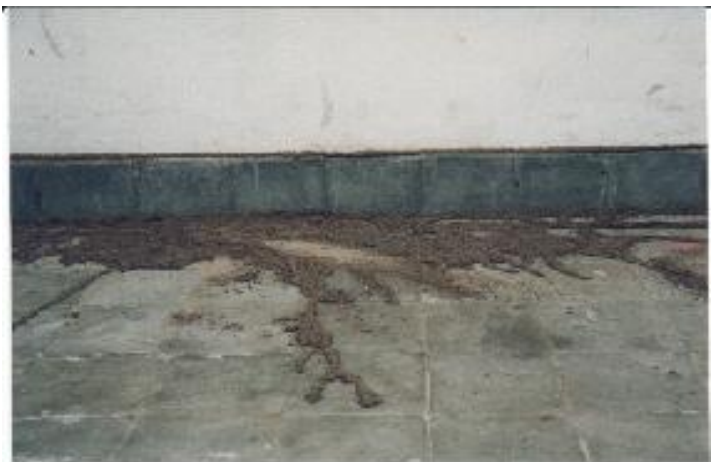

Gambar 5. Salah satu petujuk serangan rayap pada bangunan

\section{KESIMPULAN \& SARAN}

\subsection{Kesimpulan}

Pengalaman menunjukkan pembasmian rayap selama ini yang dilaksanakan secara sporadic represive mulai diketahui kekurangannya jika dibandingkan dengan cara pengendalian systemic institusional yang mengintegrasikan pengendalian rayap ke dalam siklus hidup proyek (project life cycle). Sehingga proyek yang dilaksanakan dengan tipologi Manajemen Konstruksi akan lebih berpeluang untuk merealisasikan. Pada proses tersebut sekaligus dapat dilaksanakan upaya pelestarian lingkungan.

\subsection{Saran}

Pelaksanaan 'pembasmian' rayap, terutama yang menggunakan bahan kimia secara pasti sebaiknya diganti dengan 'pengendalian' rayap yang lebih rasional. 
Jurnal APLIKASI

ISSN.1907-753X

\section{DAFTAR ACUAN}

Draft, 2005, Materi Teknis Pedoman Pembangunan Bangunan Gedung (building code) di wilayah Propinsi Nanggroe Aceh Darussalam.

Keputusan Menteri Pekerjaan Umum Republik Indonesia No 441/KPTS/1998, tentang Persyaratan Teknis Bangunan Gedung.

Keputusan Direktur Jenderal Cipta Karya, No 295/KPTS/1997, tentang Pedoman Teknis Pembangunan Bangunan Gedung Negara.
Keputusan Menteri Permukiman dan Prasarana Wilayah, No 332/KPTS/M/2002, tentang Pedoman Teknis Pembangunan Bangunan Gedung Negara.

Kumpulan Standar Nasional Indonesia (SNI) tentang Perlindungan Bangunan Terhadap Serangan Organisme Perusak.

Nandika D, 2003, RAYAP biologi dan pengendaliannya.Surakarta. Muhammadiyah University Press

Undang-undang Republik Indonesia No 28 tahun 2002. 